\title{
Estudio exploratorio-descriptivo sobre el comportamiento en la búsqueda de información de los investigadores de la UNAM que pertenecen al Sistema Nacional de Investigadores
}

\author{
Silvia Castillo Barrera ${ }^{1}$
}

Recibido: 1 Septiembre 2016 / Aceptado: 10 de mayo de 2017

Resumen. Este documento aborda el comportamiento que presentan los investigadores de la UNAM que pertenecen al Sistema Nacional de Investigadores (SNI) del área IV de Humanidades y Ciencias de la conducta al realizar su búsqueda de información para el desarrollo de sus investigaciones. La investigación consistió en averiguar cómo realizan la búsqueda de información; cuáles son las fuentes y recursos de información que utilizan; cuál es el idioma y la antigüedad en la que datan las fuentes informativas que consultan; si delegan o no la búsqueda de información a otra persona o intermediario; y si existe alguna influencia o relación en su comportamiento informativo entre los factores como la edad, categoría laboral y los años de antigüedad como investigadores en el SNI, con el uso de las bibliotecas e Internet, y con las monografías y publicaciones periódicas. Se aplicó la técnica de la encuesta haciendo uso del cuestionario, el cual se aplicó a una muestra estratificada para obtener una mayor representatividad del estudio. El análisis de los resultados fue de forma descriptiva y mediante el uso de cálculos estadísticos para constatar si existía alguna relación entre los elementos antes descritos.

Palabras clave: Comportamiento informativo; Búsqueda de información; Recursos de información; Fuentes de información; Investigadores del SNI.

\section{[en] The behavior in seeking information UNAM researchers belonging to the National System of Researchers}

\begin{abstract}
This paper addresses the behaviors of UNAM researchers belonging to the National System of Researchers (SNI) area IV of Humanities and behavior to make your search for information to develop their research. The research was to find out how to perform the search for information; What are the sources and information resources they use; what language and seniority dating consulting information sources; whether to delegate the search for information to another person or intermediary; and if there is any influence or relationship in their information behavior among factors such as age, employment status and years of service as researchers in the SNI, with the use of libraries and the Internet, and monographs and periodicals. Technical survey using the questionnaire, which was applied to a stratified sample for greater representativeness of the study was applied. The analysis of the results was descriptively and by using statistical calculations to see if there was any relationship between the elements described above.
\end{abstract}

1 Universidad Nacional Autónoma de México. Posgrado de Bibliotecología y Estudios de la Información E-mail: s1977j@yahoo.com.mx 
Keywords: Information behavior; information search; Information resources; Information sources; SNI researchers.

Sumario. 1. Introducción. 2. Los investigadores de los Subsistemas de Humanidades y de la Investigación Científica de la UNAM que pertenecen (SNI) del área IV de Humanidades y Ciencias de la conducta. 3. Metodología. 4. Análisis de resultados. 5. Discusión de resultados y conclusiones. 6. Referencias bibliográficas. 7. Anexo.

Cómo citar: Castillo Barrera, S. (2017) Estudio exploratorio-descriptivo sobre el comportamiento en la búsqueda de información de los investigadores de la UNAM que pertenecen al Sistema Nacional de Investigadores, en Revista General de Información y Documentación 27 (1), 219-246.

\section{Introducción}

En toda unidad de información, ya sea de tipo escolar, pública, universitaria o especializada, es primordial atender y satisfacer las necesidades de información de los usuarios, por ello, es importante que se investiguen, conozcan, y analicen las necesidades y el comportamiento informativo de la comunidad a la que se sirve, para planear adecuadamente los servicios, equipos, fuentes y recursos de información afines a la comunidad usuaria.

La presente investigación está enfocada a identificar el comportamiento informativo que presentan los investigadores de los subsistemas de Humanidades y de la Investigación Científica de la UNAM que pertenecen al Sistema Nacional de Investigadores (SNI), del área IV de Humanidades y Ciencias de la conducta. En la literatura existente, este tipo de comunidad de usuarios no ha sido estudiada, además de que resulta importante conocer su comportamiento informativo debido a que sus investigaciones, aportaciones y productos académicos impactan en el desarrollo de la ciencia en México.

Por lo anterior, este documento parte de los siguientes cuestionamientos: ¿Cómo realizan la búsqueda de información los investigadores de la UNAM que pertenecen al SNI del área de Humanidades y Ciencias de la conducta?; ¿Cuáles son algunos de los factores que influyen en el comportamiento informativo de dichos investigadores?; ¿Cuáles son las fuentes y recursos de información que utilizan mayormente los investigadores?; ¿De qué idioma son las fuentes de información que consultan?; ¿De qué antigüedad datan las fuentes de información que consultan los investigadores?; y ¿Los investigadores delegan las actividades de búsqueda de información a otras personas o intermediarios?. En base a estas interrogantes, los objetivos a alcanzar son: a) Establecer los mecanismos que utilizan los investigadores de la UNAM que pertenecen al SNI del área de Humanidades y Ciencias de la conducta para la búsqueda de información; b) Determinar los factores que influyen en el comportamiento informativo de los investigadores; c) Identificar los recursos de información que utilizan mayormente los investigadores; d) Identificar las fuentes de información que utilizan mayormente los investigadores; e) Determinar el idioma en el cual utilizan las fuentes; f) Señalar la antigüedad de las fuentes de información que consultan; g) Indicar si los investigadores delegan o no la búsqueda de información a otra(s) 
persona(s). Asimismo, de lo anterior se desprenden las siguientes hipótesis: a) Los investigadores de la UNAM que pertenecen al SNI del área de Humanidades y Ciencias de la conducta realizan la búsqueda en los catálogos electrónicos de las bibliotecas acerca de la temática requerida, posteriormente revisan los documentos y seleccionan el que va de acuerdo a sus necesidades de información; b) Hay factores que influyen en el comportamiento informativo de este grupo de investigadores, estos son: la edad, categoría laboral y los años de antigüedad como investigador en el SNI; c) Los investigadores que pertenecen al SNI acuden en mayor medida a la biblioteca, hemeroteca, centro de información o archivos; y, en segundo lugar, a los congresos, conferencias, seminarios y encuentros, como recursos informativos; d) Los investigadores que pertenecen al SNI utilizan mayormente, como fuentes de información, las monografías, en primer lugar, y, en segundo, las publicaciones periódicas; e) El idioma en que utilizan las fuentes de información en su mayoría es el inglés, pero además usan conjuntamente otras fuentes en idiomas como el francés y el hebreo; f) La antigüedad del material que utilizan es de más de 10 años; g) Los mismos investigadores llevan a cabo sus búsquedas de información sin requerir el apoyo de algún intermediario.

Es importante antes definir lo que se entiende por comportamiento informativo, señalando que es "la manifestación de las necesidades de información del sujeto, originadas a partir de la insuficiencia de información y conocimiento acerca de un fenómeno, objeto o acontecimiento" (Calva, 2004: 102).

Ahora bien, los estudios realizados sobre comportamiento informativo en el área de las Humanidades que se han llevado a cabo en el extranjero desde décadas atrás, nos pueden brindar un panorama sobre lo examinado en esta área. Dentro de las instituciones relevantes con aportaciones en investigación sobre comportamiento informativo, se encuentra la American Psychological Association (APA) que realizó las primeras investigaciones sobre dicha temática entre los años 1959 a 1966, cabe aludir también, el proyecto llamado Scientific Information Exchange in Psychology, iniciado en 1966 y cuya duración fue de siete años. El objetivo de dicho proyecto fue analizar el comportamiento que presentaban los psicólogos en el intercambio de información que realizaban durante los congresos de su especialidad (Sanz, 1994: 65). Posteriormente, debido a las deficiencias metodológicas que se presentaban todavía en las investigaciones, se dio paso a la creación en 1975 del Centre for Research on User Studies (CRUS) en la University of Sheffield, Inglaterra. De los estudios que se realizaron sobre comportamiento informativo en el área humanística (aunque no precisamente a investigadores) elaborados tanto en el CRUS como en otras instituciones, se pueden mencionar las conclusiones y resultados que obtuvieron algunos de los autores como Hutchins (1971), Heinzkill (1980), Corkill y Mann (1978), Stone (1980), Stieg (1981), Sanz (1994) cita a Raben y Burton (1981) y Mackesy (1982), Fulton (1991), este último autor cita resultados de Budd (1989) y Bouazza (1989), también así, Münster (2003) cita a Wiberley \& Jones (1989) y a Sievert and Sievert (1989), y Méndez (1984): 
- Las bibliotecas son de importancia para los investigadores en humanidades.

- Todo un conjunto de materiales necesitan ser consultados, así como una obra individual.

- Requieren una amplia gama de materiales y dependen especialmente de la monografía, por lo que enfatizan la importancia del material primario.

- Una serie de estudios reportaron que entre el $64 \%$ y el $82 \%$ de las citas fueron de monografías.

- Los humanistas necesitan material retrospectivo.

- Muy pocas personas cuentan con un colaborador o asistente.

- Manejan un enfoque individualista de la investigación.

- Los humanistas tienden a hacer un mayor uso de materiales en lengua extranjera, a diferencia de los físicos y los científicos sociales.

- No tienen el hábito de curiosear por los estantes de la biblioteca en búsqueda de nuevo material.

- Consultan muy poco las bases de datos para obtener información sobre un tema o para estar al día en el campo de conocimiento. Esto debido, a que las bases de datos no contaban con una planificación apropiada para los humanistas, siendo así una forma difícil de acceder a la información contenida en éstas.

- Los humanistas intercambiaban información e ideas con colegas que estaban trabajando en el mismo campo, con el fin de obtener o difundir la información.

- Una cantidad considerable de personas usaron materiales antiguos.

- Los humanistas ocupan en primer lugar las monografías seguidas por las publicaciones periódicas.

Desde que dieron inicio los diferentes estudios de usuarios sobre el comportamiento en la búsqueda de información en el área humanística, algunos de los resultados fueron posteriormente confirmados por otros autores, de igual manera que se han presentado algunas diferencias entre ellos, en donde el comportamiento del usuario cambia. Es por ello importante destacar lo esencial que es el estudio de cada comunidad en particular.

\section{Los investigadores de los Subsistemas de Humanidades y de la Investigación Científica de la UNAM que pertenecen (SNI) del área IV de Humanidades y Ciencias de la conducta}

Dentro de las actividades primordiales que se realizan en la Universidad Nacional Autónoma de México (UNAM), la investigación es la que toma gran relevancia para el desarrollo de la ciencia en nuestro país. Cabe señalar, que el $30 \%$ del total de artículos científicos publicados por académicos mexicanos corresponde a investigadores de la UNAM (Universidad Nacional Autónoma de México, 2013a). En esta casa de estudios, dicha actividad se realiza principalmente en los institutos 
y centros de investigación de la universidad, sin olvidar que también se desarrollan investigaciones en escuelas, facultades y otras entidades académicas. Éstos recintos universitarios se agrupan en dos subsistemas: Investigación en Humanidades (SIH) e Investigación Científica (SIC), ambos grandes subsistemas suman actualmente un total de 31 institutos, 16 centros, 6 programas universitarios y 1 unidad académica, y se ubican en Ciudad Universitaria y en los estados de Baja California, Querétaro, Morelos, Michoacán, Yucatán, entre otras sedes foráneas (UNAM, 2013b).

De todos los Subsistemas de la UNAM, su total de investigadores con figura académica de "Investigador de carrera" suman 2,440, pero la mayoría de ellos se encuentran agrupados en dos de los Subsistemas de la Universidad enfocados a la investigación: 1) Coordinación de Humanidades con 825, y 2) Coordinación de la Investigación Científica con 1,547 investigadores de carrera (Dirección General de Asuntos del Personal Académico, 2013), reuniendo así a 2,372 de ambos Subsistemas.

La productividad de los investigadores en México es evaluada por el Sistema Nacional de Investigadores (SNI), creado el 26 de julio de 1984 por Acuerdo Presidencial para reconocer la producción científica y tecnológica de los investigadores mexicanos. Este reconocimiento se otorga mediante una evaluación por pares y bajo el cumplimiento de ciertos criterios como: calidad de los trabajos, productividad reciente, trabajos citados, factor de impacto, aportes al desarrollo científico, tecnológico, social y cultural de México, etc., además de que se les brinda un apoyo o incentivo económico dependiendo del nivel al que pertenezcan (Consejo Nacional de Ciencia y Tecnología, 2013). Las distinciones que otorga el SNI a los investigadores, se clasifican en tres categorías: I. Candidato a Investigador Nacional; II. Investigador Nacional, con tres niveles; y III. Investigador Nacional Emérito. Las áreas del conocimiento que son consideradas por dicho sistema son siete, de las cuales para el presente trabajo la comunidad de usuarios a estudiar es la correspondiente al Área IV: Humanidades y Ciencias de la conducta del SNI, dentro de esta categoría se concentran los investigadores que generan conocimientos en las siguientes disciplinas: Antropología, Arqueología, Arquitectura, Artes y Letras, Bibliotecología, Filosofía, Historia, Lingüística, Matemáticas educativas y Enseñanza de las ciencias, Pedagogía y Psicología (Diario Oficial de la Federación, 2006).

Dentro del padrón de investigadores vigentes a enero de 2014 del SNI (CONACYT, 2014) área IV de Humanidades y Ciencias de la conducta que pertenecen a la UNAM, están contabilizados 721 investigadores, los cuales al agruparlos dentro de cada nivel del SNI resultan para el nivel 1, 348; nivel 2, 225; nivel 3, 113; y nivel C, 35. Ahora bien, de estos 721 investigadores de toda la UNAM pertenecientes al área IV del SNI, se identifica a los que están contemplados únicamente en los Subsistemas de Humanidades y de Investigación Científica, debido a que la mayoría de investigadores de carrera de la Universidad se encuentran en ambos Subsistemas, por lo que resulta de ello, una población de 376 investigadores. Una vez obtenida dicha cifra, se identificó la dependencia de la Universidad donde se localizaban los investigadores, esto para obtener una muestra estratificada por dependencia como se mostrará más adelante. 


\section{Metodología}

Para la presente investigación se identificó a la población a estudiar con las características ya mencionadas en párrafos anteriores, la cual fue de 376 investigadores. Posteriormente para determinar el tamaño de la muestra se optó por aplicar un muestreo probabilístico estratificado dada la distribución de la población mediante el uso de una fórmula ${ }^{2}$ estadística para ello (Rojas, 2005: 304). Para definir una muestra representativa de una población que consta de diferentes grupos, se requiere realizar el cálculo ${ }^{3}$ de un tamaño de muestra para el total y distribuirlo de manera proporcional entre cada uno de los grupos (Rojas, 2005: 306). La muestra que se obtuvo para el total de la población fue: $n=190$, a esta cifra se le deberá distribuir entre los demás grupos o estratos (niveles del SNI) para su adecuada representación, y a esta distribución o afijación se calcula la fracción de los grupos, es decir, la proporción que representan estos dentro de la población total. Así, las muestras de los grupos resultaron para el nivel 1, 81; para el nivel 2, 65; para el nivel 3, 36; y para el nivel C, 8 .

Una vez obtenida la muestra estratificada por niveles del SNI, se prosigue a determinar la muestra también estratificada, pero ahora por dependencia, utilizando nuevamente la fórmula $\frac{N h}{N}$, con el objeto de que cada una de ellas tenga representatividad en el estudio y sean contempladas todas las dependencias de nuestra población a investigar. Para elegir a cada uno de los investigadores que formarían parte de las muestras ya calculadas, se prosiguió a enumerar a cada investigador de la población, por dependencia y nivel del SNI, y posteriormente se seleccionó al azar el número de investigadores correspondiente a su muestra. Una vez que se obtuvo el listado de las muestras con los nombres de cada investigador, se investigó el correo electrónico de cada uno de ellos, así como el área, departamento o sitio donde se localizarían físicamente para hacerles llegar el instrumento de recolección de información.

La presente investigación fue de tipo descriptiva exploratoria, y con aplicación de la encuesta. Estudios similares realizados sobre comportamiento informativo en años anteriores, fueron llevados a cabo, por lo general, mediante esta técnica para la recopilación de la información, además de que "es una técnica muy difundida en el área de la investigación social aplicada" (Rojas, 2005: 221). Es por ello, que se optó por su elección. El instrumento que se empleó para levantar la encuesta fue el cuestionario. El diseño del mismo se puso a prueba con cinco personas, para recibir

2 La fórmula que se aplicó fue $\mathbf{n}=\frac{\frac{z^{2} q}{\mathrm{E}^{2} \mathrm{p}}}{1+\frac{1}{\mathrm{~N}}\left[\frac{\mathrm{Z}^{2} \mathrm{q}}{\mathrm{E}^{2} \mathrm{p}}-1\right]}$

En donde:

$\mathrm{N}=$ tamaño de la muestra.

$\mathrm{Z}=$ nivel de confianza $95 \%$ (1.96 en áreas bajo la curva normal)

$\mathrm{E}=$ nivel de precisión $10 \%$

$\mathrm{p}=.5$ y q $=.5$

$\mathrm{N}=376$ (total de investigadores de los cuatro niveles: 161 nivel 1; 128 nivel 2; 70 nivel 3; 17 nivel C)

$\mathrm{n}=190$

3 El cálculo se realizó con la aplicación de la fórmula $\frac{N h}{N}$ donde $N h=$ subpoblación o grupo, y $N=$ Población. 
dudas o comentarios al respecto, vía correo electrónico, y así realizar las modificaciones pertinentes y obtener el cuestionario final para la aplicación de la encuesta. Este instrumento consta de nueve preguntas: ocho de ellas cerradas y una abierta (Ver Anexo). Se decidió que fuera un cuestionario corto con el objeto de esperar una mayor respuesta, esto debido al tipo de usuarios a estudiar, pues los investigadores del SNI frecuentemente están ocupados y no tienen tiempo para participar en encuestas. Una vez devueltos los cuestionarios contestados por parte de los investigadores, se procedió a vaciar los resultados para su estudio. Para analizar si hay alguna asociación entre algunas de las variables (edad, categoría laboral y años de antigüedad como investigador en el SNI), se aplicó el análisis descriptivo y estadístico del cruce de variables con las fórmulas Chi-cuadrada y el Coeficiente de Pearson.

\section{Análisis de resultados}

De los 376 investigadores como población total, y como muestra resultante 190, se obtuvieron 140 cuestionarios contestados, esta respuesta representa el $37 \%$ de la población total, lo cual fue muy favorable para lo que se esperaba.

\subsection{Comportamiento informativo de los investigadores de la UNAM que pertenecen al (SNI) del área IV de Humanidades y Ciencias de la conducta}

A continuación se muestran los resultados obtenidos para cada una de las preguntas contenidas en el cuestionario, así como su respectivo análisis.

Para la pregunta uno del cuestionario, en la cual se preguntó a los investigadores el rango de edad al cual pertenecían, se obtuvo lo siguiente. (Ver tabla 1).

Tabla 1. Rango de edad al que pertenecen los investigadores

\begin{tabular}{|l|c|c|}
\hline \multicolumn{1}{|c|}{ Edad } & Número de investigadores & $\mathbf{\%}$ \\
\hline Menor de 25 años & 0 & 0 \\
\hline 25 a 34 años & 5 & 3 \\
\hline 35 a 44 años & 18 & 12 \\
\hline 45 a 54 años & 32 & 23 \\
\hline 55 a 64 años & 45 & 32 \\
\hline Mayor de 65 años & 40 & 30 \\
\hline Total & $\mathbf{1 4 0}$ & $\mathbf{1 0 0}$ \\
\hline
\end{tabular}

Fuente: Elaboración propia

Resultaron con mayor porcentaje el rango de 55 a 64 años, con un 32\%, así como en el de mayor de 65 años, con un $30 \%$, lo cual hace notar que la mayoría son personas de más de 55 años de edad. Esto puede inferirse porque son investigadores que pertenecen al SNI, que cuentan ya con varios años de experiencia, así como de productos de investigación de calidad, lo cual, junto con otros criterios de evaluación del SNI, los ha situado como investigadores 
nacionales. Con menores porcentajes se observa el rango de 45 a 54 años de edad con un $23 \%$, posteriormente, el rango de 35 a 44 años cuenta con un $12 \%$ y, finalmente, el de 25 a 34 años tiene únicamente un 3\%. En el rango referido a menor de 25 años de edad no se obtuvo ningún registro, debido a que es un rango de edad muy joven en el que no se contaría con los estudios y productos de investigación requeridos para pertenecer al SNI.

En la pregunta dos referente a la antigüedad de los investigadores dentro del SNI, se obtuvieron los siguientes resultados recopilados. (Ver tabla 2).

Tabla 2. Antigüedad como investigador del SNI

\begin{tabular}{|l|c|c|}
\hline \multicolumn{1}{|c|}{ Antigüedad } & Número de investigadores & \% \\
\hline Menos de 5 años & 17 & 12 \\
\hline Entre 5 a 10 años & 25 & 18 \\
\hline Entre 11 a 15 años & 44 & 32 \\
\hline Entre 16 a 20 años & 13 & 9 \\
\hline Entre 21 a 25 años & 11 & 8 \\
\hline Entre 26 a 30 años & 14 & 10 \\
\hline Más de 30 años & 16 & 11 \\
\hline Total & $\mathbf{1 4 0}$ & $\mathbf{1 0 0}$ \\
\hline
\end{tabular}

Fuente: Elaboración propia

Respecto a la antigüedad de los investigadores en el SNI, el mayor porcentaje se encuentra en el rango que va entre los 11 y los 15 años, representado por un 32\%; seguido del rango que abarca entre los 5 y los 10 años de antigüedad, con un 18\%; posteriormente le sigue el rango de menos de 5 años con $12 \%$; después el de más de 30 años con 11\%; luego el que va entre los 26 y los 30 años, con 10\%; le sigue el rango de entre 16 a 20 años con $9 \%$ y, finalmente, está el rango de entre 21 a 25 años de antigüedad en el SNI, con un $8 \%$.

Los resultados de la pregunta tres del cuestionario sobre la categoría laboral de los investigadores arrojaron lo siguiente. (Ver tabla 3). 
Tabla 3. Categoría laboral de los investigadores

\begin{tabular}{|l|c|c|}
\hline \multicolumn{1}{|c|}{ Categoría } & Número de investigadores & $\%$ \\
\hline Investigador Asociado & 15 & 11 \\
\hline Investigador Titular & 119 & 85 \\
\hline Técnico Académico Titular & 3 & 2 \\
\hline Profesor Titular & 3 & 2 \\
\hline Total & $\mathbf{1 4 0}$ & $\mathbf{1 0 0}$ \\
\hline
\end{tabular}

Fuente: Elaboración propia

En la Tabla 3 se muestran las cantidades y los porcentajes, por categoría laboral, de los investigadores. Puede notarse una gran diferencia entre el porcentaje más alto, con $85 \%$, que corresponde a la categoría de Investigador Titular y las demás categorías. Posterior a dicha categoría, sigue la de Investigador Asociado con un $11 \%$, y, en muy bajos porcentajes, se encuentran la categoría de Técnico Académico Titular y la de Profesor Titular, ambos con $2 \%$. Se puede deducir que la causa de que el mayor porcentaje se ubique en la categoría de Investigador Titular es debido a que el $98.57 \%$ de estos 140 investigadores cuenta con el grado de doctorado, nivel de estudios que es requerido y dispuesto en el art. 42 del Estatuto del Personal Académico (EPA) de la UNAM (DGAPA, 2014), además de otros requisitos, para obtener dicha categoría laboral.

Respecto a la pregunta cuatro, abierta, que se realizó sobre cuáles eran los pasos que seguían cuando realizaban búsqueda de información para sus investigaciones, de los 140 investigadores, respondieron 102 y 34, no. Mientras que 4 más de ellos no la entendieron; 2 indicando la falta de comprensión y otros 2 de ellos respondiendo cuestiones distintas.

De los que sí la contestaron se llevó a cabo el análisis y proceso de las respuestas mediante el análisis de categorías, es decir, agrupando las respuestas similares en categorías que se establecieron con base en lo que contestaron abiertamente. A estas categorías, las respuestas de cada investigador se iban codificando dentro del $1 \mathrm{er}$ hasta el $5^{\circ}$ paso, iniciando con el número 1 como el paso elegido como primer lugar y así en consecutiva, para registrar el orden en el cual llevaban a cabo su búsqueda de información.

De lo anterior se obtuvieron los siguientes resultados. (Ver tabla 4).

Como se puede ver en la Tabla 4, los pasos que realizan los investigadores en su búsqueda de información, del $1 \mathrm{er}$ al $5^{\circ}$ paso se puede resaltar la categoría más representativa por su mayor número de respuestas. Así tenemos: Dentro del 1er paso, con 30 investigadores la categoría Búsqueda bibliográfica especializada. Dentro del $2^{\circ}$ paso, con 12 investigadores la categoría Biblioteca de la Institución. Dentro del 3er paso, con 10 investigadores la categoría Internet (Google scholar con documentos descargables. Dentro del $4^{\circ}$ paso, con 2 investigadores cada una de las categorías se tiene a la Biblioteca personal, Búsqueda bibliográfica especializada, Archivo, Búsqueda en Bases de Datos de la UNAM, Intercambio con los colegas, Adquisición de libros especializados en librerías y Asistencia a 
conferencias. Finalmente, dentro del $5^{\circ}$ paso, con 4 investigadores la categoría Intercambio con colegas.

Tabla 4. Pasos que llevan a cabo los investigadores al realizar su búsqueda de información.

\begin{tabular}{|c|c|c|c|c|c|}
\hline Categorías & $\begin{array}{c}1 \mathrm{er} \\
\text { paso }\end{array}$ & $\begin{array}{c}20 \\
\text { paso }\end{array}$ & $\begin{array}{c}\text { 3er } \\
\text { paso }\end{array}$ & $\begin{array}{c}40 \\
\text { paso }\end{array}$ & $\begin{array}{c}50 \\
\text { paso }\end{array}$ \\
\hline Bibliotecas & 6 & 4 & & & \\
\hline Biblioteca personal & 4 & 4 & & 2 & \\
\hline Biblioteca de la Institución & 8 & 12 & & & \\
\hline Biblioteca extranjera & & & 6 & & \\
\hline Búsqueda bibliográfica especializada & 30 & 4 & & 2 & \\
\hline Labor de campo & 6 & 4 & 4 & & \\
\hline Búsqueda hemerográfica & 4 & 4 & & & \\
\hline Archivo & 4 & 6 & 4 & 2 & \\
\hline Búsqueda en Bases de Datos de la UNAM & 6 & 8 & 1 & 2 & \\
\hline $\begin{array}{lllll}\begin{array}{l}\text { Internet } \\
\text { descargables) }\end{array} & \text { (Google scholar con documentos } \\
\end{array}$ & 12 & 8 & 10 & & \\
\hline Intercambio con los colegas & 2 & 2 & 2 & 2 & 4 \\
\hline Bibliografía de fuentes primarias & 6 & & & & \\
\hline Consulta de diccionario y enciclopedias & 2 & & & & \\
\hline Consulta de catálogos en línea & 4 & 2 & & & \\
\hline \multicolumn{6}{|l|}{ Internet con documentos descargables } \\
\hline Bibliografía de artículos & & 4 & & & \\
\hline Internet (Redalyc) & & & 2 & & \\
\hline $\begin{array}{l}\text { Búsqueda en diferentes Bases de Datos externas a la } \\
\text { Institución }\end{array}$ & 2 & & 2 & & \\
\hline Adquisición de libros especializados en librerías & 2 & & & 2 & \\
\hline Asistencia a conferencias & & & & 2 & \\
\hline Búsqueda de fuentes estadísticas e informes & 1 & & & & \\
\hline \multicolumn{6}{|l|}{ Consulta de índices } \\
\hline Internet (páginas especializadas) & & 2 & & & \\
\hline \multicolumn{6}{|l|}{ Fuentes gráficas y orales } \\
\hline Otros, especifique & & & & & \\
\hline
\end{tabular}

Fuente: Elaboración propia

De estos resultados, se puede hacer notar que la Búsqueda bibliográfica especializada es lo que realizan primordialmente, como primer paso, los investigadores para su búsqueda de información.

Respecto a las dos preguntas sobre los recursos y fuentes de información a los que acuden los investigadores para realizar sus investigaciones, se les indicó que señalaran en orden progresivo y de importancia, del 1 al 5, siendo el 1 el más importante. Para ambas preguntas, el investigador estaba en la libertad de anotar el número de opciones que considerara necesarias, pudiendo así repetir, si lo deseaba, algunos recursos con el mismo número de prioridad. Cabe señalar, que dentro de 
las opciones a elegir dentro de los recursos de información indicados en el cuestionario, éstos se incluyeron de manera general, es decir, podían pertenecer tanto a la propia institución donde laboraban como a otras externas.

Ahora bien, en respuesta a la pregunta sobre los recursos a los que acuden los investigadores para obtener información cuando realizan una búsqueda, se obtuvo lo que siguiente. (Ver tabla 5).

Tabla 5. Recursos que utilizan mayormente los investigadores cuando realizan búsqueda de información. Lugar que le asignan al recurso por importancia del 1-5 (siendo el 1 más importante)

\begin{tabular}{|l|c|c|c|c|c|}
\hline \multicolumn{1}{|c|}{ Recursos de información } & $\mathbf{1}$ & $\mathbf{2}$ & $\mathbf{3}$ & $\mathbf{4}$ & $\mathbf{5}$ \\
\hline Colegas documentación, & 70 & 6 & 11 & 9 & 10 \\
\hline $\begin{array}{l}\text { Biblioteca, hemeroteca, centro de } \\
\text { archivos }\end{array}$ & 54 & 13 & 15 & 8 \\
\hline Catálogo electrónico & 10 & 18 & 9 & 9 & 2 \\
\hline Colección particular & 0 & 7 & 13 & 3 & 8 \\
\hline Colección particular de otros colegas & 7 & 10 & 2 & 0 & 3 \\
\hline Experiencia personal & 1 & 2 & 8 & 20 & 9 \\
\hline Expertos en el área & 3 & 6 & 11 & 14 & 11 \\
\hline Congresos, conferencias, seminarios, encuentros & 17 & 23 & 17 & 20 & 9 \\
\hline Bases de datos bibliográficas & 25 & 21 & 16 & 20 & 26 \\
\hline $\begin{array}{l}\text { Internet (motores de búsqueda, yahoo, google, } \\
\text { altavista, redes sociales) }\end{array}$ & 0 & 1 & 6 & 3 & 13 \\
\hline Librerías & 0 & 1 & 0 & 0 & 0 \\
\hline Otro, especifique & & & & \\
\hline
\end{tabular}

Fuente: Parte de los recursos de información enlistados fueron tomados de Calva (2004). Encuesta; Elaboración propia.

Este cuestionamiento fue contestado por todos los participantes. Como se muestra en la Tabla 5, el primer y segundo lugar lo ocupa la opción de biblioteca, hemeroteca, centro de documentación, archivos, con 70 respuestas y 54 respectivamente; en tercer lugar son las bases de datos bibliográficas; en cuarto lugar se localizaron los expertos en el área, las bases de datos bibliográficas y el Internet; y, finalmente, en quinto lugar, con 26 respuestas, está el Internet. Como se observa, sigue prevaleciendo en primer lugar el uso de las bibliotecas, siendo éstas un recurso fundamental para nuestra comunidad de estudio.

La pregunta referente a las fuentes de información a las que acuden los investigadores para desarrollar sus investigaciones, arrojó lo que a continuación se muestra. (Ver tabla 6 ). 
Tabla 6. Fuentes que utilizan mayormente los investigadores cuando realizan búsqueda de información. Lugar que le asignan a la fuente por importancia del 1-5 (siendo el 1 más importante)

\begin{tabular}{|l|c|c|c|c|c|}
\hline \multicolumn{1}{|c|}{ Fuentes de información } & $\mathbf{1}$ & $\mathbf{2}$ & $\mathbf{3}$ & $\mathbf{4}$ & $\mathbf{5}$ \\
\hline Monografías (libros, tesis, etc.) & 71 & 21 & 20 & 5 & 6 \\
\hline $\begin{array}{l}\text { Publicaciones periódicas (revistas, anuarios, } \\
\text { diarios, etc.) }\end{array}$ & 57 & 53 & 6 & 7 & 3 \\
\hline $\begin{array}{l}\text { Publicaciones oficiales (informes de } \\
\text { organismos nacionales y extranjeros, etc.) }\end{array}$ & 4 & 11 & 20 & 11 & 10 \\
\hline $\begin{array}{l}\text { Obras de consulta (diccionarios, enciclopedias, } \\
\text { directorios, manuales, etc.) }\end{array}$ & 3 & 9 & 29 & 30 & 15 \\
\hline $\begin{array}{l}\text { Fuentes referenciales (catálogos, índices, } \\
\text { abstracts, bibliografías, etc. }\end{array}$ & 10 & 19 & 28 & 28 & 19 \\
\hline Materiales audiovisuales (videos, casetes, etc.) & 1 & 3 & 5 & 10 & 9 \\
\hline $\begin{array}{l}\text { Documentos técnicos (partituras, patentes, } \\
\text { planos, mapas, etc.) }\end{array}$ & 2 & 4 & 8 & 5 & 8 \\
\hline Otros, especifique & 1 & 1 & 0 & 1 & 0 \\
\hline
\end{tabular}

Fuente: El listado de las fuentes de información fue tomado de Calva (2004). Encuesta; Elaboración propia.

En la Tabla 6 se muestran las cinco fuentes de información que utilizan mayormente los investigadores, por orden de importancia. En primer lugar, con 71 respuestas, se sitúan las monografías; en segundo lugar, con 53 respuestas, están las publicaciones periódicas; en tercer y cuarto lugar, con 29 y 30 respuestas respectivamente, se encuentran las obras de consulta; en quinto lugar con 19 respuestas están las fuentes referenciales. Dentro de las fuentes que señalaron como otros, encontramos: manuscritos, fotografías, obras de arte, extractos documentales puestos en línea, códices indígenas y textos en lengua náhuatl. Además, algunos mencionaron que utilizaban todos los materiales pero que las fuentes dependen del objeto de estudio. Sólo un investigador no contestó la pregunta. Estos resultados muestran que las monografías siguen prevaleciendo como las fuentes primordiales en comparación a las publicaciones periódicas, este tipo de comportamiento se ha visto en estudios similares realizados en décadas anteriores, lo cual deja al descubierto que la información primaria es importante para la comunidad de estudio.

Respecto al reactivo siete, sobre el idioma en el cual consultan las fuentes de información los investigadores, señalaron lo siguiente. (Ver tabla 7). 
Tabla 7. Idioma de las fuentes de información que consultan los investigadores.

\begin{tabular}{|c|c|c|}
\hline Idioma & Número de investigadores & $\%$ \\
\hline Español & 125 & 89 \\
\hline Inglés & 130 & 93 \\
\hline Francés & 84 & 60 \\
\hline Alemán & 23 & 16 \\
\hline Hebreo & 6 & 4 \\
\hline No entendió la pregunta & 1 & 0.7 \\
\hline \multicolumn{3}{|l|}{ Otro (s), especifique } \\
\hline Portugués & 19 & 13 \\
\hline Italiano & 20 & 14 \\
\hline Ruso & 3 & 2 \\
\hline Latín & 6 & 4 \\
\hline Griego & 3 & 2 \\
\hline Rumano & 1 & 0.7 \\
\hline Catalán & 2 & 1 \\
\hline Náhuatl & 2 & 1 \\
\hline Maya & 1 & 0.7 \\
\hline Zapoteco & 1 & 0.7 \\
\hline Yucateco & 1 & 0.7 \\
\hline Mixteco & 1 & 0.7 \\
\hline Tzeltal & 1 & 0.7 \\
\hline Tzotzil & 1 & 0.7 \\
\hline
\end{tabular}

Fuente: Elaboración propia

La Tabla 7 muestra que las fuentes de información que consultan los investigadores en su mayoría son en idioma inglés, con un número de 130 respuestas, siendo así un 93\% del total; seguido del idioma español con 125 respuestas y con un 89\%; el idioma francés ocupó el tercer lugar con 84 respuestas y con un 60\%; el cuarto idioma es el alemán con 23 respuestas y con 16\%; y dentro del rubro de otros idiomas, mencionaron catorce de ellos, posicionándose en quinto lugar el italiano con 20 respuestas, sumando un porcentaje del 14\%; el sexto lugar fue el portugués con 19 respuestas y un $13 \%$; el séptimo lugar lo obtuvieron el latín y el hebreo, ambos con 6 respuestas y con un 4\%; el octavo sitio fue para el ruso y el griego, con 3 respuestas y $2 \%$ para cada uno; el noveno lugar lo ocuparon el catalán y el náhuatl con 2 respuestas y 1\% para ambos; finalmente, en décimo sitio, se encuentran el rumano, el maya, el zapoteco, el yucateco, el mixteco, el tzeltal y el tzotzil con 1 respuesta y con $.7 \%$ para cada uno. Sólo hubo un investigador que no contestó la pregunta argumentando que no la entendía. Estas respuestas indican que el idioma más utilizado en las fuentes de información que son consultadas es en un idioma extranjero, en este caso el inglés, y con un uso menor a éste es el idioma español y francés. Además de que usan conjuntamente, en menor porcentaje, fuentes en otros idiomas. Este comportamiento se ha presentado, de manera similar, en algunos estudios hechos en el extranjero, por ejemplo en el realizado por Hutchins en 1971, en el cual un idioma extranjero, en este caso el francés, fue el más 
usado por los humanistas (Sanz, 1994: 79). Las respuestas a la pregunta ocho, la cual hace referencia a la antigüedad del material que utilizan los investigadores en su búsqueda de información, se enumeran a continuación. (Ver tabla 8).

Tabla 8. Antigüedad del material que consultan los investigadores.

\begin{tabular}{|l|c|c|}
\hline \multicolumn{1}{|c|}{ Antigüedad del Material } & Número de investigadores & \% \\
\hline Últimos 5 años & 84 & 60 \\
\hline Más de 5 y hasta 10 años & 81 & 51 \\
\hline Más de 10 años & 80 & 50 \\
\hline Otra, especifique & 2 & 1 \\
\hline Siglo XVI a la fecha & 4 & 3 \\
\hline Siglos XVI y XVII & 5 & 4 \\
\hline Siglo XVIII & 5 & 4 \\
\hline Siglo XIX & 3 & 2 \\
\hline Siglo XX & 1 & 0.7 \\
\hline Desde 1500 d.n.e & 3 & 2 \\
\hline
\end{tabular}

Fuente: Elaboración propia

La Tabla 8 señala que la antigüedad del material que utilizan los investigadores es en su mayoría de los últimos 5 años, esto se obtuvo de las 84 respuestas obtenidas, que reflejan un $60 \%$ del total; el segundo lugar es para el material de entre 5 y 10 años, con 81 respuestas y con un 51\%; y, en tercero, se encuentra aquél cuya antigüedad es de más de 10 años, con 80 respuestas, esto es con un $50 \%$. Cabe destacar que, aunque el mayor porcentaje pertenece al rango de los últimos 5 años, no es mucha la diferencia entre éste y los otros dos rangos de antigüedad, de esto puede inferirse que utilizan conjuntamente material de antigüedad variada. Esta pregunta fue contestada por todos los participantes.

En cuanto a la última pregunta, la cual cuestiona a los investigadores si delegan o no la búsqueda de información en algún ayudante o colaborador, se obtuvo lo siguiente. (Ver tabla 9).

Tabla 9. Delegar la búsqueda de información en algún ayudante o colaborador

\begin{tabular}{|l|c|c|}
\hline \multicolumn{1}{|c|}{ Delegar la búsqueda } & Número de investigadores & \% \\
\hline Siempre & 2 & 1 \\
\hline Casi siempre & 18 & 13 \\
\hline Nunca & 87 & 62 \\
\hline Casi nunca & 28 & 20 \\
\hline A veces & 5 & 4 \\
\hline Total & $\mathbf{1 4 0}$ & $\mathbf{1 0 0}$ \\
\hline
\end{tabular}

Fuente: Elaboración propia 
La Tabla 9 refleja, con 87 respuestas, que nuestra comunidad de estudio suele no delegar nunca la actividad de búsqueda de información en algún ayudante o colaborador, lo cual representa a nivel porcentual un $62 \%$; posteriormente, con 28 respuestas, aparece la opción que indica que casi nunca delegan dicho trabajo, siendo un $20 \%$ quienes indicaron esto; como tercera opción, con 18 respuestas, con un $13 \%$ arrojó que casi siempre delegan la búsqueda; en cuarto lugar aparece la opción a veces con 5 respuestas y un 4\%; finalmente como último lugar, está la elección siempre, lo cual indica que sólo 2 investigadores delegan siempre esta actividad, es decir, un 1\%. De estos resultados sobresale la respuesta que indica que los investigadores nunca delegan la actividad de búsqueda de información en algún colaborador o ayudante, lo cual confirma que este tipo de comportamiento sigue prevaleciendo en comparación con estudios similares realizados en el extranjero, donde también se presenta un enfoque individualista en la investigación.

\subsection{Cruce de variables}

Para identificar si existen o no algunas variables o factores que influyan en el comportamiento informativo de este grupo de investigadores, es importante llevar a cabo el cálculo de las variables elegidas para este trabajo, las cuales son: edad, categoría laboral y años de antigüedad como investigador y cómo influyen estos factores con el uso de los dos recursos de información (las bibliotecas e Internet) seleccionados por los investigadores como primera opción, y con el uso de las dos fuentes de información (monografías y publicaciones periódicas) elegidas por ellos, también como primeras opciones. Esto se hizo con la finalidad de encontrar alguna asociación entre las variables y el tipo de comportamiento que presenta nuestra comunidad de estudio. Las técnicas para este análisis de cruce de variables son de coeficientes de asociación y correlación, para ello se aplicaron las respectivas fórmulas ${ }^{4}$ estadísticas (Rojas, 2005, 423). Además se analizó la asociación de los resultados con base en una escala ${ }^{5}$ que mide la magnitud de la asociación o correlación de los valores (Rojas, 2005, 417).

Ahora bien, los investigadores que indicaron como primera opción el inciso b) la biblioteca, hemeroteca, centro de documentación, archivos, para la búsqueda informativa, se muestran abajo. (Ver tabla 10).

\footnotetext{
Se utilizaron las fórmulas Chi cuadrada: $X^{2}=\sum(f o-f e)^{2} / f e, y$ Coeficiente de Pearson $C=\sqrt{X^{2} / X^{2}}+N$ Los valores que puede alcanzar oscilan entre $-1 \mathrm{y}+1$; cuando es igual a -1 indicará una completa disociación entre las variables, y si es igual a +1 mostrará una asociación total. En caso de que el valor sea igual a cero, se concluye que no hay asociación o relación entre las variables. Para los demás valores puede emplear la siguiente regla:

Valor del coeficiente

Menos de .25

De .25 a .45

De .46 a .55

De .56 a .75

De .76 en adelante

Magnitud de la asociación o correlación

Baja

Media baja

Media

Media alta

Alta
} 
Tabla 10. Rango de edad de los investigadores que señalaron, en primer lugar, el inciso b) La biblioteca, hemeroteca, centro de documentación, archivos, para realizar búsqueda de información.

\begin{tabular}{|l|c|c|c|}
\hline \multicolumn{1}{|c|}{ Rango de edad } & $\begin{array}{c}\text { Número de } \\
\text { investigadores }\end{array}$ & $\begin{array}{c}\text { Investigadores que señalaron } \\
\text { el inciso b) la biblioteca, } \\
\text { hemeroteca, centro de } \\
\text { documentación, archivos } \\
\text { para realizar búsqueda de } \\
\text { información }\end{array}$ & $\%$ \\
\hline Menor de 25 años & & 2 & \\
\hline 25 a 34 años & 5 & 7 & 40 \\
\hline 35 a 44 años & 18 & 15 & 39 \\
\hline 45 a 54 años & 32 & 26 & 58 \\
\hline 55 a 64 años & 45 & 20 & 50 \\
\hline Mayor de 65 años & 40 & & \\
\hline
\end{tabular}

Fuente: Elaboración propia

Se obtuvo que 26 de 45 personas son del rango de edad entre 55 a 64 años, siendo un 58\%; después con 20 de 40 entre el rango mayor de 65 años, con un $50 \% ; 15$ de 32 investigadores entre 45 a 54 años, correspondiente a un $47 \% ; 2$ de 5 entre el rango de 25 a 34 años, siendo un $40 \%$; y finalmente 7 de 18 sujetos entre 35 a 44 años, con un 39\%. Estos resultados analizados con las fórmulas de asociación se tiene: $\left(\mathrm{X}^{2}\right)=0.7$ y $\mathrm{C}=0.0608$, lo cual apunta a que no hay asociación o relación entre los rangos de edad de los sujetos y el uso de la biblioteca, hemeroteca, centro de documentación, archivos, para la búsqueda informativa que ellos realizan.

En cuanto a los investigadores que señalaron utilizar el Internet como primera opción para realizar su búsqueda informativa, acorde a los diferentes rangos de edad, se muestran a continuación. (Ver tabla 11).

Tabla 11. Rango de edad de los investigadores que señalaron, en primer lugar, utilizar el Internet para la búsqueda de información.

\begin{tabular}{|l|c|c|c|}
\hline \multicolumn{1}{|c|}{ Rango de edad } & $\begin{array}{c}\text { Número de } \\
\text { investigadores }\end{array}$ & $\begin{array}{c}\text { Investigadores que utilizan el Internet } \\
\text { para la búsqueda de información }\end{array}$ & $\%$ \\
\hline Menor de 25 años & & 3 & \\
\hline 25 a 34 años & 5 & 4 & 60 \\
\hline 35 a 44 años & 18 & 8 & 22 \\
\hline 45 a 54 años & 32 & 4 & 25 \\
\hline 55 a 64 años & 45 & 6 & 15 \\
\hline Mayor de 65 años & 40 & 3 & \\
\hline
\end{tabular}

Fuente: Elaboración propia

Los resultados señalan, que 3 de los 5 investigadores pertenecen al rango de edad de 25 a 34 años, siendo un $60 \%$; posteriormente se obtuvieron 8 de los 32 entre el rango 45 a 54 años, correspondiendo un 25\%; 4 de los 18 al de 35 de 44 
años, con un 22\%; 6 de los 40 en el rango mayor a 65 años, siendo un $15 \%$; y por último, con 4 de los 45 de entre 55 a 64 años, con un 9\%. Dichos resultados calculados mediante las medidas de asociación se obtuvo: $\left(X^{2}\right)=7$ y $C=0.2017$, lo cual indica que existe una relación o asociación baja entre los rangos de edad de los investigadores y el uso del Internet para la búsqueda de información.

Respecto a los investigadores que dijeron en primer lugar utilizar las monografías para realizar su búsqueda informativa conforme a su rango de edad, se indica a continuación. (Ver tabla 12).

Tabla 12. Rango de edad de los investigadores que señalaron, en primer lugar, utilizar las monografías para la búsqueda de información.

\begin{tabular}{|l|c|c|c|}
\hline \multicolumn{1}{|c|}{ Rango de edad } & $\begin{array}{c}\text { Número de } \\
\text { investigadores }\end{array}$ & $\begin{array}{c}\text { Investigadores que utilizan las } \\
\text { monografías para la búsqueda de inf. }\end{array}$ & $\%$ \\
\hline Menor de 25 años & & 3 & 60 \\
\hline 25 a 34 años & 5 & 11 & 61 \\
\hline 35 a 44 años & 18 & 19 & 59 \\
\hline 45 a 54 años & 32 & 22 & 49 \\
\hline 55 a 64 años & 45 & 16 & 40 \\
\hline Mayor de 65 años & 40 & & \\
\hline
\end{tabular}

Fuente: Elaboración propia

Las respuestas obtenidas indican que 11 de 18 investigadores de entre el rango de edad son de 35 a 44 años, con un 61\%; 3 de 5 entre el rango de 25 a 34 años, con $60 \%$; 19 de 32 entre el rango 45 a 54 años, con un 59\%; 22 de 45 entre el rango 55 a 64 años, correspondiente a un 49\%; y finalmente 16 de 40 entre el rango mayor de 65 años de edad, con un 40\%. Calculando la asociación entre variables de los resultados anteriores, tenemos que $\left(\mathrm{X}^{2}\right)=8.0537$ y $\mathrm{C}=0.1917$, lo cual señala que se tiene una relación o asociación baja entre los rangos de edad de los investigadores y el uso de las monografías para la búsqueda informativa.

Los investigadores que respondieron en primer lugar a utilizar las publicaciones periódicas para su búsqueda informativa, son los siguientes. (Ver tabla 13).

Tabla 13. Rango de edad de los investigadores que señalaron, en primer lugar, utilizar publicaciones periódicas para la búsqueda de información.

\begin{tabular}{|l|c|c|c|}
\hline \multicolumn{1}{|c|}{ Rango de edad } & $\begin{array}{c}\text { Número de } \\
\text { investigadores }\end{array}$ & $\begin{array}{c}\text { Investigadores que utilizan las publicaciones } \\
\text { periódicas para la búsqueda de información }\end{array}$ & $\%$ \\
\hline Menor de 25 años & & & \\
\hline 25 a 34 años & 5 & 6 & 40 \\
\hline 35 a 44 años & 18 & 12 & 33 \\
\hline 45 a 54 años & 32 & 18 & 37 \\
\hline 55 a 64 años & 45 & 19 & 40 \\
\hline Mayor de 65 años & 40 & 2 & 48 \\
\hline
\end{tabular}

Fuente: Elaboración propia 
Los resultados señalan que el mayor número obtenido fue 19 de 40 investigadores entre el rango mayor de 65 años de edad, con el 48\%; 18 de 45 entre 55 a 64 años y 2 de 5 entre 25 a 34 años, siendo para ambos casos el $40 \%$; posteriormente 12 de 32 entre 45 a 54 años, con el 37\%; y por último 6 de 18 de entre 35 a 44 años, correspondiente al 33\%. Realizado el cálculo de las medidas de asociación se tiene que: $\left(\mathrm{X}^{2}\right)=5.9893 \mathrm{C}=0.17175$, lo cual indica que hay una relación o asociación baja entre los rangos de edad de los investigadores y el uso de las publicaciones periódicas para la búsqueda informativa de los investigadores.

Ahora bien, para los investigadores que señalaron utilizar el Internet como primera opción para realizar su búsqueda informativa, en los diferentes rubros de antigüedad como investigadores del SNI, se señalan a continuación. (Ver tabla 14).

Tabla 14. Años de antigüedad como investigador del SNI de los investigadores que señalaron, en primer lugar, utilizar el Internet para la búsqueda de información.

\begin{tabular}{|l|c|c|c|}
\hline $\begin{array}{c}\text { Antigüedad como } \\
\text { investigador del SNI }\end{array}$ & $\begin{array}{c}\text { Número de } \\
\text { investigadores }\end{array}$ & $\begin{array}{c}\text { Investigadores que utilizan el } \\
\text { Internet para la búsqueda de } \\
\text { información }\end{array}$ & $\%$ \\
\hline Menos de 5 años & 17 & 4 & 23 \\
\hline Entre 5 a 10 años & 25 & 4 & 16 \\
\hline Entre 11 a 15 años & 44 & 6 & 14 \\
\hline Entre 16 a 20 años & 13 & 3 & 23 \\
\hline Entre 21 a 25 años & 11 & 3 & 21 \\
\hline Entre 26 a 30 años & 14 & 1 & 6 \\
\hline Más de 30 años & 16 & & \\
\hline
\end{tabular}

Fuente: Elaboración propia

Se obtuvo 4 de 17 investigadores con menos de 5 años de antigüedad, y 3 de 13 entre 16 a 20 años, siendo para ambos casos un 23\%; posteriormente 3 de 14 entre 26 a 30 años, con un 21\%; 4 de 25 entre 5 a 10 años, con un 16\%; 6 de 44 entre 11 a 15 años, siendo un 14\%; 1 de 11 entre 21 a 25 años, correspondiente a un 9\%; y finalmente 1 de 16 para más de 30 años, con un $6 \%$. Con estos resultados se calculó la relación o asociación entre variables, dando como resultado: $\left(\mathrm{X}^{2}\right)=$ 5.0639 y $\mathrm{C}=0.1741$, esto indica que existe una relación o asociación baja entre los años de antigüedad como investigador del SNI y el uso del Internet para la búsqueda de información.

En cuanto a los investigadores que apuntaron como primera opción el inciso b) la biblioteca, hemeroteca, centro de documentación, archivos, para la búsqueda informativa, conforme a sus años de antigüedad como investigadores del SNI, se muestra abajo. (Ver tabla 15). 
Tabla 15. Años de antigüedad como investigador del SNI de los investigadores que señalaron, en primer lugar, el inciso b) La biblioteca, hemeroteca, centro de documentación, archivos, para realizar búsqueda de información.

\begin{tabular}{|l|c|c|c|}
\hline $\begin{array}{c}\text { Antigüedad como } \\
\text { investigador del SNI }\end{array}$ & $\begin{array}{c}\text { Número de } \\
\text { investigadores }\end{array}$ & $\begin{array}{c}\text { Investigadores que señalaron el } \\
\text { inciso b) la biblioteca, hemeroteca, } \\
\text { centro de documentación, archivos } \\
\text { para realizar búsqueda de } \\
\text { información }\end{array}$ & $\%$ \\
\hline Menos de 5 años & 17 & 9 & 53 \\
\hline Entre 5 a 10 años & 25 & 15 & 60 \\
\hline Entre 11 a 15 años & 44 & 15 & 34 \\
\hline Entre 16 a 20 años & 13 & 2 & 15 \\
\hline Entre 21 a 25 años & 11 & 4 & 36 \\
\hline Entre 26 a 30 años & 14 & 9 & 56 \\
\hline Más de 30 años & 16 & 9 & \\
\hline
\end{tabular}

Fuente: Elaboración propia

Las respuestas arrojaron que 9 de 14 personas son de entre 26 a 30 años, siendo un $64 \%$; 15 de 25 entre 5 a 10 años, con un $60 \%$; 9 de 16 para más de 30 años, siendo un 56\%; 9 de 17 para menos de 5 años, con un 53\%; 4 de 11 entre 21 a 25 años, con un $36 \%$; 15 de 44 entre 11 a 15 años, con un 34\%; y finalmente 2 de 13 entre 16 a 20 años, correspondiente a un 15\%. Estos resultados analizados con las fórmulas de asociación se tiene: $\left(\mathrm{X}^{2}\right)=5.1294 \mathrm{C}=0.1569$, lo cual determina que existe una relación o asociación baja entre los años de antigüedad como investigador del SNI y el uso de la biblioteca, hemeroteca, centro de documentación, archivos, para la búsqueda informativa que ellos realizan.

Respecto a los investigadores que dijeron en primer lugar utilizar las monografías para realizar su búsqueda informativa, conforme a sus años de antigüedad como investigadores del SNI, se obtuvieron los siguientes resultados. (Ver tabla 16).

Tabla 16. Años de antigüedad como investigador del SNI de los investigadores que señalaron, en primer lugar, utilizar las monografías para la búsqueda de información.

\begin{tabular}{|l|c|c|c|}
\hline $\begin{array}{c}\text { Antigüedad como } \\
\text { investigador del SNI }\end{array}$ & $\begin{array}{c}\text { Número de } \\
\text { investigadores }\end{array}$ & $\begin{array}{c}\text { Investigadores que utilizan las } \\
\text { monografías para la búsqueda } \\
\text { de información }\end{array}$ & $\%$ \\
\hline Menos de 5 años & 17 & 11 & 65 \\
\hline Entre 5 a 10 años & 25 & 14 & 56 \\
\hline Entre 11 a 15 años & 44 & 18 & 41 \\
\hline Entre 16 a 20 años & 13 & 5 & 38 \\
\hline Entre 21 a 25 años & 11 & 3 & 64 \\
\hline Entre 26 a 30 años & 14 & 7 & 21 \\
\hline Más de 30 años & 16 & 34 \\
\hline
\end{tabular}

Fuente: Elaboración propia 
Los resultados indican que 11 de 17 investigadores se sitúan en menos de 5 años, es el 65\%; posteriormente 7 de 11 entre 21 a 25 años, siendo el 64\%; 14 de 25 entre 5 a 10 años, siendo un 56\%; 7 de 16 para más de 30 años, siendo un $44 \%$; 18 de 44 entre 11 a 15 años, siendo un $41 \%$; 5 de 13 entre 16 a 20 años, siendo un $38 \%$; y por último 3 de 14 entre 26 a 30 años, siendo un $21 \%$. Realizando el cálculo correspondiente a las variables de asociación, se tiene que: $\left(\mathrm{X}^{2}\right)=8.5453 \mathrm{y}$ $\mathrm{C}=0.2000$, lo cual indica que se tiene una relación o asociación baja entre la antigüedad como investigador del SNI de los investigadores y el uso de las monografías para la búsqueda informativa.

En lo concerniente a las respuestas de los investigadores que señalaron, en primer lugar utilizar las publicaciones periódicas para su búsqueda informativa, conforme a sus años de antigüedad como investigadores del SNI, se obtuvo lo siguiente. (Ver tabla 17).

Tabla 17. Años de antigüedad como investigador del SNI de los investigadores que señalaron, en primer lugar, utilizar publicaciones periódicas para la búsqueda de información.

\begin{tabular}{|l|c|c|c|}
\hline $\begin{array}{c}\text { Antigüedad como } \\
\text { investigador del SNI }\end{array}$ & $\begin{array}{c}\text { Número de } \\
\text { investigadores }\end{array}$ & $\begin{array}{c}\text { Investigadores que utilizan las } \\
\text { publicaciones periódicas para la } \\
\text { búsqueda de información }\end{array}$ & $\%$ \\
\hline Menos de 5 años & 17 & 5 & 29 \\
\hline Entre 5 a 10 años & 25 & 10 & 40 \\
\hline Entre 11 a 15 años & 44 & 12 & 27 \\
\hline Entre 16 a 20 años & 13 & 5 & 38 \\
\hline Entre 21 a 25 años & 11 & 3 & 27 \\
\hline Entre 26 a 30 años & 14 & 9 & 64 \\
\hline Más de 30 años & 16 & 7 & 44 \\
\hline
\end{tabular}

Fuente: Elaboración propia

Las respuestas muestran que 9 de 14 entre 26 a 30 años de antigüedad, corresponde al mayor porcentaje con 64\%; después 7 de 16 para más de 30 años, siendo un $44 \%$; 10 de 25 entre 5 a 10 años, con un $40 \%$; 5 de 13 entre 16 a 20 años, con un 38\%; 5 de 17 para menos de 5 años, siendo un 29\%; y por último 12 de 44, entre 11 a 15 años, y 3 de 11 entre 21 a 25 años, correspondiente para ambos un $27 \%$. Calculando la asociación se tiene que: $\left(\mathrm{X}^{2}\right)=5.9389$ y $\mathrm{C}=0.17365$, lo que indica que hay una relación o asociación baja entre la antigüedad como investigadores del SNI de los investigadores y el uso de las publicaciones periódicas para la búsqueda informativa de ellos.

En cuanto a los investigadores que expresaron utilizar el Internet como primera opción para realizar su búsqueda informativa, en las diferentes categorías laborales, son los que se exponen a continuación. (Ver tabla 18). 
Tabla 18. Categoría laboral de los investigadores que señalaron, en primer lugar, utilizar el Internet para la búsqueda de información.

\begin{tabular}{|l|c|c|c|}
\hline \multicolumn{1}{|c|}{ Categoría laboral } & $\begin{array}{c}\text { Número de } \\
\text { investigadores }\end{array}$ & $\begin{array}{c}\text { Investigadores que utilizan el } \\
\text { Internet para la búsqueda de } \\
\text { información }\end{array}$ & $\%$ \\
\hline Investigador Asociado & 15 & 6 & 40 \\
\hline Investigador Titular & 119 & 16 & 13 \\
\hline Profesor Titular & 3 & 1 & 33 \\
\hline
\end{tabular}

Fuente: Elaboración propia

Se obtuvo 6 de 15 investigadores dentro de la categoría laboral de Investigador Asociado, siendo un 40\%; 1 de 3 en la categoría de Profesor Titular, con un 33\%; y por último 16 de 119 en la categoría de Investigador Titular, con un 13\%. De esto calculando su asociación entre variables tenemos lo siguiente: $\left(\mathrm{X}^{2}\right)=4.5034$ y $\mathrm{C}=$ 0.16545 , por lo que existe una relación o asociación baja entre las categorías laborales de los investigadores y el uso del Internet para la búsqueda informativa.

Respecto a los investigadores que apuntaron como primera opción el inciso b) la biblioteca, hemeroteca, centro de documentación, archivos, para la búsqueda informativa, en sus diferentes categorías laborales, se muestra lo siguiente. (Ver tabla 19)

Tabla 19. Categoría laboral de los investigadores que señalaron, en primer lugar, el inciso

b) La biblioteca, hemeroteca, centro de documentación, archivos, para la búsqueda de información.

\begin{tabular}{|l|c|c|c|}
\hline \multicolumn{1}{|c|}{ Categoría laboral } & $\begin{array}{c}\text { Número de } \\
\text { investigadores }\end{array}$ & $\begin{array}{c}\text { Investigadores que señalaron el inciso } \\
\text { b) la biblioteca, hemeroteca, centro de } \\
\text { documentación, archivos para realizar } \\
\text { búsqueda de información }\end{array}$ & $\%$ \\
\hline Investigador Asociado & 15 & 7 & 47 \\
\hline Investigador Titular & 119 & 62 & 52 \\
\hline $\begin{array}{l}\text { Técnico académico } \\
\text { Titular }\end{array}$ & 3 & 1 & 33 \\
\hline Profesor Titular & 3 & 1 & 33 \\
\hline
\end{tabular}

Fuente: Elaboración propia

Los resultados indican que 62 de 119 investigadores son de la categoría de Investigador Titular, siendo un 52\%; después 7 de 15 Investigadores Asociados, con un 47\%; y por último 1 de 3 de Técnico académico titular y Profesor Titular respectivamente, y siendo para ambos un 33\%. Estos resultados analizados con las fórmulas de asociación se tiene: $\left(\mathrm{X}^{2}\right)=10.2158$ y $\mathrm{C}=0.2148$, lo que indica que existe una relación o asociación baja entre la categoría laboral de los investigadores y el uso de la biblioteca, hemeroteca, centro de documentación, archivos, para la búsqueda informativa que ellos realizan. 
De los investigadores que dijeron en primer lugar utilizar las monografías para realizar su búsqueda informativa, conforme a su categoría laboral, se enlistan abajo. (Ver tabla 20).

Tabla 20. Categoría laboral de los investigadores que señalaron, en primer lugar, utilizar las monografías para la búsqueda de información.

\begin{tabular}{|l|c|c|c|}
\hline \multicolumn{1}{|c|}{ Categoría laboral } & $\begin{array}{c}\text { Número de } \\
\text { investigadores }\end{array}$ & $\begin{array}{c}\text { Investigadores que utilizan las } \\
\text { monografías para la búsqueda } \\
\text { de información }\end{array}$ & $\%$ \\
\hline Investigador Asociado & 15 & 10 & 67 \\
\hline Investigador Titular & 119 & 59 & 49 \\
\hline Técnico académico Titular & 3 & 1 & 33 \\
\hline Profesor Titular & 3 & 1 & 33 \\
\hline
\end{tabular}

Fuente: Elaboración propia

Se observa que 10 de 15 investigadores de la categoría Investigador Asociado, corresponde al 67\%; 59 de 119 para Investigador titular, con un 49\%; y finalmente 1 de 3 para Técnico académico titular, y Profesor titular, con un 33\% para ambos. Realizando el cálculo correspondiente a las variables de asociación, se tiene que: $\left(X^{2}\right)=7.5299$ y $C=0.1856$, lo cual señala que se tiene una relación o asociación baja entre la categoría laboral del investigador y el uso de las monografías para su búsqueda informativa.

Los investigadores que apuntaron como primer lugar utilizar las publicaciones periódicas para su búsqueda informativa, conforme a su categoría laboral, se muestran a continuación. (Ver tabla 21).

Tabla 21. Categoría laboral de los investigadores que señalaron, en primer lugar, utilizar publicaciones periódicas para la búsqueda de información.

\begin{tabular}{|l|c|c|c|}
\hline \multicolumn{1}{|c|}{ Categoría laboral } & \multicolumn{1}{|c|}{$\begin{array}{c}\text { Número de } \\
\text { investigadores }\end{array}$} & $\begin{array}{c}\text { Investigadores que utilizan las } \\
\text { publicaciones periódicas para la } \\
\text { búsqueda de información }\end{array}$ & $\%$ \\
\hline Investigador Asociado & 15 & 3 & 20 \\
Investigador Titular & 119 & 50 & 42 \\
\hline
\end{tabular}

Fuente: Elaboración propia

Los resultados señalan con el mayor número es 50 de 119 investigadores con la categoría de Investigador titular, siendo un 42\%; y por último 3 de 15 Investigadores asociados, con un $20 \%$. Estos resultados analizados con las fórmulas de asociación se tiene: $\left(\mathrm{X}^{2}\right)=1.3499$ y $\mathrm{C}=0.0846$, lo que indica que no existe asociación entre las categorías laborales y el utilizar las publicaciones periódicas para la búsqueda informativa. 


\section{Discusión de resultados y conclusiones}

Con base en los cuestionamientos que dieron lugar en la presente investigación para conocer el comportamiento informativo que presentan los investigadores de los subsistemas de Humanidades y de la Investigación Científica de la UNAM que pertenecen al SNI, del área IV de Humanidades y Ciencias de la Conducta, partimos de la primera cuestión respondiendo lo siguiente:

Los investigadores realizan su búsqueda de información iniciando con la búsqueda bibliográfica especializada, la mayoría de ellos no especificaron qué medios utilizaban para realizar dicha búsqueda. Una vez que identifican su bibliografía prosiguen a acudir a la biblioteca de su institución, lo cual deja ver la importancia que tiene para ellos las bibliotecas, ya que revisan las fuentes bibliográficas que les proveen éstas, ya sea de forma impresa o electrónica. La relevancia que los investigadores les dan a estas unidades de información coincide con lo encontrado en un estudio realizado por Corkill y Mann (1978), donde también se presenta este interés. Posteriormente, en los casos en que su biblioteca no cuenta con los documentos identificados dentro de su bibliografía especializada utilizan Internet para descargar documentos en Google scholar. Para ahondar más en sus investigaciones, pueden acudir ya sea a su biblioteca personal, a realizar nuevamente búsqueda bibliográfica especializada, al archivo; a buscar en bases de datos de la UNAM, a intercambio con los colegas, a adquisición de libros especializados en librerías, o a asistir a conferencias. Además como último paso, recurren a los colegas expertos en el tema para mayor información, aunque no fue un paso señalado en primer lugar por los investigadores, sí fue mencionado dentro del paso cuatro y cinco. El intercambio con colegas coincide también con lo que Corkill y Mann (1978) encontraron en su estudio donde señalan que hay "un intercambio de información e ideas con otros colegas que trabajan el mismo campo, con el fin de obtener o difundir la información". Estos resultados confrontados con la hipótesis no queda corroborada, ya que en la búsqueda bibliográfica especializada que señalan los investigadores no especifican si la realizan consultando el catálogo electrónico, como se indicó en la hipótesis.

En cuanto a algunos de los factores que pueden influir en el comportamiento informativo de los investigadores, se puede aludir que con base en la asociación de las variables de edad, categoría laboral y años de antigüedad como investigador del SNI, con el uso de los dos recursos de información (las bibliotecas e Internet) seleccionados por los investigadores como primera opción y dichas variables con el uso de las fuentes de información (monografías y publicaciones periódicas) que se analizaron, en la mayoría resultó con una asociación baja y sólo en dos asociaciones: rango de edad con biblioteca y categoría laboral con publicaciones periódicas, la relación fue nula. Esto indica que no influyen los aspectos como la edad, categoría laboral y antigüedad laboral en el SNI, en el comportamiento informativo de dichos investigadores, como se había afirmado en la hipótesis.

Respecto a los recursos y fuentes de información que usan en su mayoría, los resultados arrojaron que en lo que respecta a los recursos de información, el más importante que utilizan fue el rubro de biblioteca, hemeroteca, centro de 
documentación, archivos. Con ello se comprueba parte de la hipótesis, es decir, en lo que respecta a este rubro de recursos, ya que no se comprobó que el rubro de los congresos, conferencias, seminarios y encuentros, haya sido el segundo rubro de recursos de predilección como se señaló en la hipótesis.

Los resultados sobre el uso de las bases de datos de los investigadores del SNI, indican que fue el tercer recurso más importante en la búsqueda de información. Esto hace notar que su uso no es pobre, en comparación a lo que señala Sanz (1994) en su obra, sobre el uso de las bases de datos por los humanistas, él indica que "este tipo de usuarios consulta muy poco las bases de datos para obtener información sobre un tema determinado o para estar al día en su campo de conocimiento" (Sanz, 1994: 78). Además, autores como Méndez (1984), indicaron una menor frecuencia de su consulta. Por su parte, Raben y Burton (1981), además de Mackesy (1982), señalaron como principal problema de esto "la falta de una planificación adecuada en el desarrollo de las bases de datos específicas para los humanistas, de tal manera que a veces era excesivamente complejo acceder a la información que contenían..." (Sanz, 1994: 78). Confrontando lo anterior, se puede señalar que las bases de datos que en décadas pasadas se venían utilizando contaban con un diseño y herramientas diferentes a las actuales, como lo indican y coincido con los autores, Raben, Burton (1981) y Mackesy (1982), sobre las causas por las que no eran casi consultadas dichas herramientas. Actualmente el diseño de las bases de datos ha mejorado gracias a los avances tecnológicos, siendo más fácil su uso.

En lo que corresponde a la predilección de las fuentes de información a las que acuden los investigadores, resultó en primer lugar, las monografías y en segunda instancia las publicaciones periódicas. Esto coincide con los resultados obtenidos en un estudio por Heinzkill (1980), además de otros realizados por Budd (1989), donde reporta que entre el $64 \%$ y el $82 \%$ de las citas fueron de monografías, indiscutiblemente esto indica la importancia de estas últimas para las investigaciones en humanidades. Con esto, queda comprobada la hipótesis plateada para este rubro.

El idioma de las fuentes de información que consultan mayormente los investigadores fue el inglés, como el idioma más señalado por los investigadores, lo cual muestra que consultan en su mayoría materiales en idioma extranjero. Esto último de igual forma se presentó en estudios realizados por otros autores, como Hutchins (1971). Como segundo idioma fue el español, posteriormente fueron mencionados los idiomas: francés, alemán, italiano, portugués, latín, hebreo, ruso, catalán, náhuatl, etc. Estos resultados comprueban la hipótesis, en que el idioma inglés es el más utilizado en las fuentes de información los investigadores, además de usar conjuntamente fuentes en otros idiomas como el francés y hebreo.

Respecto a la antigüedad de los materiales que consultan los investigadores resultó que es variada, ya que las cantidades obtenidas muestran una muy ligera diferencia entre los rangos de antigüedad. Esto es, que el material consultado puede ser de los últimos 5 años, de 5 a 10 años o de más de 10 años. Este hecho no concuerda con lo obtenido por Corkill y Mann (1978), donde señalaron que muchas personas usaron materiales antiguos. Para este rubro, la hipótesis no se 
confirma, ya que se planteó en la misma, que la antigüedad del material que utilizan los investigadores era de más de 10 años.

En lo que respecta a delegar o no la búsqueda informativa a otras personas, resultó que los investigadores no delegan la búsqueda informativa a otro u otros colaboradores o ayudantes, lo cual se confirma con estudios realizados por otros autores como Stone (1980) realizados en décadas pasadas. Con esto se corrobora la hipótesis respectiva.

Finalmente, cabe señalar que este estudio es un acercamiento y un parteaguas a nuevos aspectos a tratar de manera más profunda sobre el comportamiento informativo de los investigadores analizados, para así aportar más literatura sobre la temática, ya que aún es escasa en esta área.

\section{Referencias bibliográficas}

Bouazza, A. (1989). Information user studies. Encyclopedia of Library and Information Science, 44, 144-166.

Budd, J. (1989). Research in two cultures. Collection Management, 11 (3-4), 1-23.

Calva González, J. J. (2004). Las necesidades de información: fundamentos teóricos y métodos. México: UNAM/CUIB.

CONACyT. (2013). Sistema Nacional de Investigadores. Obtenido de: http://www.conacyt.gob.mx/sni/Paginas/default.aspx [Consulta: 28/10/2013].

- (2014). Sistema Nacional de Investigadores. Investigadores vigentes a enero de 2014. Obtenido de: http://www.conacyt.gob.mx/SNI/_layouts/xlviewer.aspx?id=/SNI/ Documents/VIGENTES_SNI2014.xlsx [Consulta: 23/02/2014].

Corkill, C., M. Mann. (1978). Information needs in the humanities: two postal surveys. Sheffield: University of Sheffield, Centre for Research on User Studies.

DGAPA (Dirección General de Asuntos del Personal Académico). (2013). Personal académico en los subsistemas de acuerdo con la figura. Obtenido de: http://gapa.unam.mx/html/estadisticas/Estadistica-Qna2213.pdf [Consulta: 23/11/2013].

- (2014). Estatuto del personal académico de la UNAM (EPA). Obtenido de: http://dgapa.unam.mx/html/normatividad/epa.html [Consulta: 05/05/2014].

Diario Oficial de la Federación. (2013). Reglamento del Sistema Nacional de Investigadores, Primera sección. Obtenido de: http://diariooficial.segob.gob.mx/nota_detalle.php?codigo $=4932567 \&$ fecha $=26 / 09 / 2006$ [Consulta: 28/10/2013].

Fulton, C. (1991). Humanists as information users: a review of the literature. Australian Academic \& Research Libraries, 2 (3), 188-197.

Heinzkill, R. (1980). Characteristics of references in selected scholarly English Literary journals. Library Quarterly, 50 (3), 352-365.

Hutchins, W. J., Pargeter, L. J., y Saunders. (1971). The language barrier: a study in depth of the place of foreign language materials in the research activity of an academic community. Sheffield: University of Sheffield.

Mackesy, E. M. (1982). A perspective on secondary access services in the humanities. Journal of the American Society for Information Science, 33 (2), 146-151.

Méndez, A. (1984). An analysis of humanists requests received by an Information Service for the Humanities. Journal of Information Science, 9, 97-105. 
Münster, I. (2003). Un estudio de las necesidades de información, hábitos y características de investigadores en Humanidades y Ciencias Sociales. Información, cultura y sociedad.

Obtenido de:http://www.scielo.org.ar/scielo.php?script=sci_arttext\&pid=S1851174020030001000 04lng=es\&nr=iso [Consulta: 16/10/2013].

Raben, J., y Burton, S. K. (1981). Information systems and services in the arts and humanities. Annual Review of Information Science and Technology, 16, 247-266.

Rojas Soriano, R. (2005). Guía para realizar investigaciones sociales. México: Plaza y Valdés.

Sanz Casado, E. (1994). Manual de estudios de usuarios. Madrid: Fundación Germán Sánchez Ruipérez.

Sievert, D. y Sievert, M. E. (1989). Philosophical research: report from the field. En Humanists at work: disciplinary perspectives and personal reflections. (pp. 79-94). Chicago: University Illinois at Chicago.

Stieg, M. F. (1981). The information of needs of historians. College and research libraries, $42(6), 549-560$.

Stone, S. (1980). CRUS humanities research programme. En S. Stone (ed.), Humanities information research proceedings of a seminar. (pp. 15-26). Sheffield, UK: University of Sheffield.

UNAM (Universidad Nacional Autónoma de México). (2013). Agenda estadística UNAM 2013. Obtenido de: http://www.planeacion.unam.mx/Agenda/2013/disco/\# [Consulta: 24/10/2013].

- (2013). Portal de estadística universitaria. Obtenido de: http://www.estadistica.unam.mx/numeralia/ [Consulta: 24/10/2013].

Wiberley, S. E. y Jones, W. G. (1989). Patterns of information seeking in the Humanities. College and Research Libraries, 50 (6), 638-645.

\section{Anexo}

\section{CUESTIONARIO}

Le solicito amablemente indique las respuestas que considere adecuadas desde su punto de vista. Los datos que usted proporcione tienen gran importancia.

Instrucciones: Marque por favor con una " $\mathrm{x}$ " las respuestas a las preguntas solicitadas, y en orden progresivo del 1 al 5 donde se le solicite (siendo el número 1 el más importante), además de escribir la información necesaria en los espacios correspondientes para ello.

1. Rango de edad al que pertenece:

2. Antigüedad como investigador del SNI:
a) Menor de 25 años
( )
b) 25 a 34 años
()
a) Menos de 5 años
b) Entre 5 a 10 años
c) 35 a 44 años
c) Entre 5 a 10 años
d) 45 a 54 años
d) Entre 16 a 20 años ( )
e) 55 a 64 años
e) Entre 21 a 25 años ( )
f) Mayor de 65 años
f) Entre 26 a 30 años ( )
g) Entre 26 a 30 años ( ) 
3. Categoría laboral:

4. ¿Cuáles son los pasos que sigue cuando busca información para sus investigaciones?

5. Cuando realiza búsqueda de información, ¿A qué recursos acude para obtenerla? (Señale en orden progresivo y de importancia del 1 al 5, siendo el 1 el más importante. Puede repetir números si lo considera)
a) Colegas.
( )
b) Biblioteca, hemeroteca, centro de documentación, archivos
( )
c) Catálogo electrónico
d) Colección particular.
( )
( )
e) Colección particular de otros colegas.
( )
f) Experiencia personal.
( )
g) Expertos en el área.
h) Congresos, conferencias, seminarios, encuentros.
( )
i) Bases de datos bibliográficas.
j) Internet (motores de búsqueda, yahoo, google, altavista, redes sociales) ( )
k) Librerías
( )
1) Otro, especifique

6. ¿Cuáles son las fuentes de información a las que acude para realizar sus investigaciones? (Señale por orden progresivo y de importancia del 1 al 5, siendo el 1 el más importante. Puede repetir números si lo considera) 
a) Monografías (libros, tesis, etc.)

b) Publicaciones periódicas (revistas, anuarios, diarios, etc.)

( )

c) Publicaciones oficiales (informes de organismos nacionales y extranjeros, etc.) ( )

d) Obras de consulta (diccionarios, enciclopedias, directorios, manuales, etc.)

( )

e) Fuentes referenciales (catálogos, índices, abstracts, bibliografías, etc.).

( )

f) Materiales audiovisuales (videos, casetes, etc.)

( )

g) Documentos técnicos (partituras, patentes, planos, mapas, etc.)

h) Otros, especifique

7. ¿Cuál es el idioma de las fuentes de información que consulta?
a) Español
b) Inglés
c) Francés
d) Alemán
e) Hebreo
f) Otro (s), especifique

( )

( )

8. Indique la antigüedad del material que utiliza para sus investigaciones:
a) Últimos 5 años.
b) Más de 5 y hasta 10 años
( )
c) Más de 10 años
d) Otra, especifique

9. ¿Delega la búsqueda de información en algún ayudante o colaborador?
a) Siempre
b) Casi siempre
c) Nunca
d) Casi nunca

( ) 